\title{
Comparative Study of Preoperative Radiological Findings with Intraoperative Surgical Findings in Squamosal Type of Chronic Otitis Media
}

\author{
Sanjana Pradeep ${ }^{1}$, Swaroop Dev², Jyothi Swarup Raju3, Shravya Pasunuti ${ }^{4}$ \\ 1, 2, 3,4 Department of ENT, Sri Siddhartha Medical College and Hospital, Tumkur, Karnataka, India.
}

\section{ABSTRACT}

\section{BACKGROUND}

Chronic otitis media (COM) of squamosal type is associated with cholestatoma with potential complications. Clinical examination and high resolution computed tomography (HRCT) scans are necessary to assess the disease site and extension. The purpose of the study was to compare the preoperative HRCT findings with the intraoperative surgical findings in squamosal type of chronic otitis media as well as various parameters in HRCT temporal bone and intraoperative findings.

\section{METHODS}

A prospective study was conducted on 30 patients aged between 18 and 60 years of both the genders who presented with chronic otitis media squamosal type, for a period of 22 months who attended the outpatient department of ENT.

\section{RESULTS}

HRCT findings and intraoperative findings were compared and results were analysed. Facial canal erosion ( $P$ - 0.0031), tegmen plate erosion ( $\mathrm{P}$ - 0.0001), sigmoid sinus plate erosion ( $\mathrm{P}-0.002)$ were found to be statistically significant. Lateral semicircular canal fistula $(P-0.36)$ and ossicular status malleus ( $\mathrm{P}-1.000)$, incus $(\mathrm{P}-0.949)$, stapes suprastructure (P - 0.984), and stapes footplate erosion ( $\mathrm{P}$ - 0.977) were found to be statistically insignificant.

\section{CONCLUSIONS}

In our study, HRCT imaging for COM squamosal type, accurately depicted the soft tissue mass, erosion of tegmen plate, sigmoid sinus plate, scutum, lateral semicircular canal fistula, incus and suprastructure of stapes erosion and the same were found intraoperatively as well. Our study showed good comparison between the preoperative HRCT scans and the surgical findings in cholesteatoma cases. HRCT is confirmed to be valuable in the diagnosis and in guiding the surgical management of cholesteatoma.

\section{KEY WORDS}

Chronic Otitis Media, Cholesteatoma, HRCT Temporal Bone, Modified Radical Mastoidectomy

\author{
Corresponding Author: \\ Dr. Swaroop Dev. M, \\ Associate Professor, \\ Sri Siddhartha Medical College \\ and Hospital, Agalakote, \\ Tumkur - 572107, \\ Karnataka, India. \\ E-mail: swaroopdev5@gmail.com
}

DOI: $10.14260 / j e m d s / 2021 / 385$

How to Cite This Article:

Pradeep S, DevS, Raju JS, et al.. Comparative study of pre-operative radiological findings with intra-operative surgical findings in squamosal type of chronic otitis media. J Evolution Med Dent Sci 2021;10(25):18621865, DOI: 10.14260/jemds/2021/385

Submission 11-03-2021,

Peer Review 26-04-2021,

Acceptance 30-04-2021,

Published 21-06-2021.

Copyright (c) 2021 Sanjana Pradeep et al.. This is an open access article distributed under Creative Commons Attribution License [Attribution 4.0 International (CC BY 4.0)] 


\section{BACKGROUND}

Chronic otitis media of squamosal type has cholesteatoma which can be associated with many intratemporal and intracranial complications. Chronic otitis media of squamosal type is classified into congential and acquired. Acquired squamosal chronic otitis media is further divided into primary acquired and secondary acquired. Squamosal chronic otitis media is also classified as active and inactive chronic otitis media. Active squamosal disease presents with foul smelling otorrhoea and hearing impairment. Many patients complain of hearing impairment and are unaware of the ear discharge as the quantity of pus is scanty and they dry up to form crusts. The crust is mistaken for wax.

Examination under microscope is usually required to allow thorough cleaning of the discharge and to confirm the diagnosis. In very inflamed ear, a cholesteatoma may not be visible at first presentation. Sometimes, aural polyp can be seen obscuring the attic or posterior pars tensa. Pars tensa or pars flaccid regions must be examined by removing the crusts if present. Inactive squamosal type of chronic otitis media presents as retraction pocket. They may reach such a size and configuration that they cease to become self-cleansing and accumulate inactive squamous debris. This debris may become infected and clinically characterized by repeated episodes of discharge, often with symptom free intervals in between; as in intermittently active squamous COM.

Retraction may lead to histological changes in the tympanic membrane with loss of elasticity and rigidity so that the tympanic membrane no longer drives the ossicular chain or areas of the tympanic membrane may be eroded leaving a perforation. Tympanic retraction may also damage the middle ear structures, like long process of incus.

Spread of cholesteatoma commonly occurs in the following pathways.

a) Posterior epitympanum cholesteatoma: The most common route of cholesteatoma extension from the epitympanum is posteriorly from prussack's space. This route passes through the superior incudal space, which lies lateral to the body of incus and then traverses the aditus and antrum to enter the mastoid. Posterior epitympanum cholesteatoma usually reaches the middle ear by descending through the floor of the prussak's space into the posterior space of Von Troeltsch.

b) Posterior mesotympanum cholesteatoma: The sinus tympani and facial recess are commonly involved. Extension of posterior mesotympanic cholesteatoma to the mastoid occurs via the posterior tympanic isthmus and the inferior incudal space. In contrast to posterior epitympanic cholesteatoma, mastoid extension of posterior mesotympanic cholesteatoma typically passes medial to the malleus and incus.

c) Anterior epitympanum cholesteatoma: The floor of the anterior epitympanum is related to the horizontal portion of the facial nerve and the geniculate ganglion. Anterior inferior extension into the supratubal recess is common. These cholesteatomas reach the middle ear by descending through the anterior pouch of Von Troeltsch. ${ }^{1}$

The role of imaging in the assessment of temporal bone pathology has been enhanced by the refinement of the diagnostic equipment and new techniques. ${ }^{2}$

A major advance in imaging of the ear structures has occurred with a development of high resolution computed tomography. Thin section HRCT allows by means of special algorithms, imaging of osseous structures up to a spatial resolution of 0.45 to $0.65 \mathrm{~mm}$. Early recognition of squamosal chronic otitis media is important to adopt a surgical procedure to prevent grave intratemporal and intracranial complications. The present study has been undertaken to study the role of HRCT as a diagnostic modality in squamosal chronic otitis media. HRCT has an advantage of excellent topographic visualization devoid of artifacts and also from superimposition of structures. By comparing preoperative HRCT temporal bone findings and intraoperative surgical findings, it helps the surgeon to formulate proper surgical intervention and to avoid intraoperative complications by understanding the anatomical variations of temporal bone. In otological surgeries the preoperative assessment of facial canal, lateral semicircular canal, tegmen plate, ossicular status are important to avoid many preoperative complications. ${ }^{3}$

\section{METHODS}

A Prospective study was conducted for a period of 22 months from November 2018 to September 2020, on 30 patients aged between 18 and 60 years, of both genders who presented with chronic otitis media squamosal type attending the outpatient department of ENT. All patients underwent HRCT temporal bone scans and thereafter with informed consent all patients were subjected to either canal wall up or canal wall down procedures. Patients with Mucosal COM, Temporal bone malignancy and Revision surgery for squamosal COM were excluded from the study. During surgical procedure intraoperative findings were compared with the preoperative HRCT temporal findings and changes were noted.

\section{Statistical Analysis}

The collected data was entered into an excel sheet. After appropriate data collection, the data sheet was transferred and analysed using Statistical Package for social sciences (SPSS) Software version - 20. To compare the categorial qualitative data variables, Fischer exact test and $\mathrm{Z}$ tests were used.

\section{RESULTS}

The age group of the study population was in the range of 18 $60 \mathrm{yrs}$. Most of the subjects were between 31 and 40yrs $(\mathrm{N}=$ $15,50 \%$ ) with mean age being 36.57 . In our study we found that male patients $(\mathrm{N}=17 ; 56.7 \%)$ were more than females $(\mathrm{N}$ $=13 ; 43.3 \%$ ).

\begin{tabular}{|cccc|}
\hline Age Groups (Yrs.) & Gender & Total (\%) \\
$18-20$ & 1 & Male & 3.3 \\
$21-30$ & 2 & 0 & 36.7 \\
$31-40$ & 10 & 9 & 50.0 \\
$41-50$ & 0 & 5 & 6.7 \\
$51-60$ & 0 & 1 & 3.3 \\
Total & 13 & 17 & 100 \\
\hline \multicolumn{4}{c}{ Table 1. Age and Gender Distribution } \\
\hline
\end{tabular}

In our study laterality was compared and we found that right ear ( $\mathrm{N}=16 ; 53.33 \%)$ was more affected than left ear. ( $\mathrm{n}$ 
$=14 ; 46.7 \%$ ). In our study, canal wall down procedure (CWD) was done in 28 patients (93.3\%) and canal wall up (CWU) procedure was done in 02 patients $(6.7 \%)$.

\begin{tabular}{|ccc|}
\hline Procedure & No. of Cases & Percentage \% \\
CWD & 28 & $93.3 \%$ \\
CWU & 2 & $6.7 \%$ \\
Total & $\mathbf{3 0}$ & $\mathbf{1 0 0 . 0}$ \\
\hline \multicolumn{3}{|c|}{ Table 2. Surgical Procedure } \\
\hline
\end{tabular}

\section{Comparison between HRCT and Intraoperative Findings}

Incus was found eroded in 26 cases (86.6\%), malleus in 04 cases (13.33\%), suprastructure of stapes in 17 cases $(56.66$ $\%$ ), and foot plate of stapes was eroded in 05 cases (16.6\%). Intraoperatively incus was found eroded in 24 cases (80 \%), malleus was found eroded in 04 cases (13.33\%), suprastructure of stapes in 18 cases $(60 \%)$ and foot plate of stapes in 3 cases (10\%),

\begin{tabular}{|c|c|c|c|c|c|c|}
\hline \multirow{2}{*}{\multicolumn{2}{|c|}{ Ossicles }} & \multicolumn{2}{|c|}{ CT Findings } & \multicolumn{2}{|c|}{ IOP Findings } & \multirow{2}{*}{$\begin{array}{c}\text { Z Test } \\
\text { P - Value }\end{array}$} \\
\hline & & $\begin{array}{c}\text { No. of } \\
\text { Subjects }\end{array}$ & $\%$ & No. of Subjects & $\%$ & \\
\hline \multirow{2}{*}{ Malleus } & Intact & 26 & 86.7 & 26 & 86.7 & \multirow{2}{*}{1.000} \\
\hline & Eroded & 04 & 13.3 & 04 & 13.3 & \\
\hline \multirow{2}{*}{ Incus } & Intact & 4 & 13.3 & 6 & 20.0 & \multirow{3}{*}{0.9497} \\
\hline & Eroded & 26 & 86.7 & 24 & 80.0 & \\
\hline \multirow{2}{*}{$\begin{array}{c}\text { Stapes } \\
\text { Supra } \\
\text { structure }\end{array}$} & Intact & 13 & 43.3 & 12 & 40.0 & \\
\hline & Eroded & 17 & 56.7 & 18 & 60.0 & 0.9843 \\
\hline \multirow{3}{*}{\multicolumn{2}{|c|}{$\begin{array}{c}\text { Stapes Intact } \\
\text { Footplate Eroded } \\
\text { Total }\end{array}$}} & 25 & 83.3 & 27 & 90.0 & \multirow{3}{*}{0.9779} \\
\hline & & 5 & 16.7 & 3 & 10.0 & \\
\hline & & 30 & 100.0 & 30 & 100.0 & \\
\hline \multicolumn{7}{|c|}{ Table 3. Ossicular Status } \\
\hline
\end{tabular}

In our study on HRCT, lateral semi-circular canal fistula was found in 4 cases (13.3\%) and absent in 26 cases (86.66 $\%$ ), intraoperatively lateral semi-circular erosion was found in 3 cases (10\%) and intact in 27 cases (90\%). P - Value was statistically insignificant 0.36 ( $>0.05$ ). On HRCT, facial canal erosion was seen in 6 cases $(20.0 \%)$ and intact in 24 cases (80 $\%)$, intra operatively facial canal erosion was found eroded in 03 cases $(10 \%)$ and intact in 27 cases $(90 \%)$. The P - value was statistically significant $0.0031(<0.05)$.

\begin{tabular}{|c|c|c|c|c|}
\hline \multirow{2}{*}{ LSCC } & \multicolumn{2}{|c|}{ CT Findings } & \multicolumn{2}{|c|}{ IOP Findings } \\
\hline & No. of Subjects & $\%$ & No. of Subjects & $\%$ \\
\hline Intact & 26 & 86.66 & 27 & 90 \\
\hline Fistula & 04 & 13.33 & 03 & 10 \\
\hline \multirow[t]{2}{*}{ Total } & 30 & 100.0 & 30 & 100.0 \\
\hline & \multicolumn{2}{|c|}{ CT findings } & \multicolumn{2}{|c|}{ IOP findings } \\
\hline Facial canal & No. of Subjects & $\%$ & No. of Subjects & $\%$ \\
\hline Eroded & 6 & 20.0 & 3 & 10.0 \\
\hline Intact & 24 & 80 & 27 & 90 \\
\hline \multirow[t]{2}{*}{ Total } & 30 & 100.0 & 30 & 100.0 \\
\hline & \multicolumn{2}{|c|}{ CT Findings } & \multicolumn{2}{|c|}{ IOP Findings } \\
\hline Tegmen plate & No. of Subjects & $\%$ & No. of Subjects & $\%$ \\
\hline Eroded & 4 & 13.3 & 4 & 13.3 \\
\hline Intact & 26 & 86.7 & 4 & 89.7 \\
\hline Total & 30 & 100.0 & 30 & 100.0 \\
\hline \multicolumn{5}{|c|}{ Table 4. LSCC, Facial Canal and Tegmen Plate Erosion } \\
\hline
\end{tabular}

Tegmen plate erosion on HRCT was found eroded in 4 cases $(13.3 \%)$, and was intact in 26 cases (86.7\%), intra operatively Tegmen plate erosion was found in 4 cases $(13.3$ $\%)$, and was found intact in 26 cases $(89.7 \%)$. The $P$ value was statistically significant with $0.0001(<0.05)$. In our study on HRCT, sigmoid sinus was found intact in 28 cases $(93.3 \%)$ and eroded in 2 cases (6.7\%), intra operatively sigmoid sinus was found intact in 28 cases (93.3\%) and eroded in 2 cases $(6.7$ $\%$ ). The P value was statistically significant with 0.002 ( < 0.05).

\begin{tabular}{|ccccc|}
\hline Sigmoid Sinus & $\begin{array}{c}\text { CT Findings } \\
\text { No. Subjects }\end{array}$ & $\mathbf{\%}$ & $\begin{array}{c}\text { IOP Findings } \\
\text { No. of Subjects }\end{array}$ & $\mathbf{\%}$ \\
Eroded & 2 & 6.7 & 2 & 6.7 \\
Intact & 28 & 93.3 & 28 & 93.3 \\
Total & $\mathbf{3 0}$ & $\mathbf{1 0 0 . 0}$ & $\mathbf{3 0}$ & $\mathbf{1 0 0 . 0}$ \\
\hline \multicolumn{4}{c}{ Table 5. Sigmoid Sinus Erosion } \\
\hline
\end{tabular}

\section{DISCUSSION}

The temporal bone is a complex anatomical area that is made up of five osseous components: the squamous, mastoid, petrous, tympanic and styloid portions of the temporal bone. Anatomically, the temporal bone may be separated into five distinct regions that demonstrates some specific type of pathologies, and can dictate the optimum imaging method depending on the area of concern and the pathology suspected. These anatomical sub divisions of the temporal bone are; the external ear, the middle ear and mastoid, inner ear, the internal auditory canal (IAC) and the facial nerve canal.

Multi detector CT scanning allows extremely quick acquisition of imaging of the temporal bones. CT utilizes ionizing radiation. The data acquired is volume, which can be reconstructed in a variety of imaging planes depending upon the anatomical area being scrutinized. Typical temporal bone CT images are acquired at a thickness of $0.5-0.6 \mathrm{~mm}$, and they provide excellent bony detail of external auditory canal (EAC), middle ear and mastoid, ossicular chain, inner ear, and the facial nerve canal.

The inner ear structures of temporal bone are oriented to external landmark of the skull, making it possible to align the section plane to structures that need to be evaluated. The temporal bone has a high inherent radiation attenuation contrast, having both the densest bone in the body as well as air filled spaces. The HRCT scan is the standard imaging technique for the temporal bone. Scanning is usually done in axial, coronal and sagittal planes with reconstruction.

The diagnosis of cholesteatoma is usually made on otologic examination. In cases where the diagnosis is not obvious, HRCT may demonstrate a soft tissue mass with characteristic ossicular erosion. The hallmark of cholesteatoma is the presence of soft tissue density in the middle ear cavity, ossicular erosions, and middle ear structures. These changes, when associated with bony expansion of the middle ear cavity, are highly suggestive of cholesteatoma.

Signs indicating cholesteatoma in the attic include erosion or destruction of scutum (lateral attic wall), widening of the aditus and antrum. Cholesteatoma can lead to erosion of facial canal which causes facial nerve paralysis. It can also lead to erosion of lateral semicircular canal which may result into fistula formation, dehiscence of tegmen tympani, dehiscence of sigmoid sinus plate, erosion of external auditory canal and automastoidectomy.

Although otoscopic recognition of cholesteatoma is often reliable, in diagnosing Squamosal COM, imaging modalities should be used on all patients suspected of harboring a cholesteatoma to determine the presence of gross or subtle changes and the presence of complications, which are mostly due to bone erosions. The specific issues that must be assessed on imaging studies and that will affect the surgical treatment are bone erosion and the degree of extension. HRCT is sensitive for the detection of early bone erosions and detailed 
imaging of the soft tissue extent of middle ear cholesteatoma provides information that may affect their surgical resection.

The most common age group affected in our study was 31 to 41 years with a mean age of 36.5 years. Male preponderance was seen in our study ( $\mathrm{N}=17$ with $56.7 \%$ ). Right ear was more affected than the left in our study and same was found in a study done by Anelise Abrabao et al. ${ }^{4}$ In a study conducted by Mehrad Rogha et al. ${ }^{5}$ in 2014, found mean age of presentation at 38.2 with male prepondarence of $55.6 \%$ of cases which was similar to our study. The ossicular status showed the long process of the incus as the commonest ossicle to get eroded in $86.6 \%$ of patients on HRCT with similar erosions found intraoperatively among (80 \%) of patients. In a study conducted by Shreeya v Kulkarni et al. ${ }^{6}$ in 2019 on 100 patients and Chakenahalli. P Nanjaraj et al. ${ }^{7}$ on 50 patients in 2013 also found that long process of the incus was the commonest ossicle to get eroded both on HRCT and intraoperatively. The lateral semi-circular canal erosion was found in 4 cases on HRCT and only 3 cases intraoperatively in our study. In other studies conducted by Ginni Dutta et al. ${ }^{3}$ in 2014 and Gulay madan et al. ${ }^{8}$ in 2015 showed similar number of cases of semicircular canal erosion both on HRCT and intraoperatively. Facial canal erosion was seen in 6 patients on HRCT but only 3 patients had facial canal erosion intraoperatively. In a similar study conducted by Ranjan kumar et al. ${ }^{9}$ in 2015 on 50 patients showed facial canal erosion on HRCT in 5 cases but only 2 patients had erosions intraoperatively which was similar to our study.

Among the parameters, tegmen plate erosion was found in 4 cases on HRCT and similar was found intraoperatively. In the similar study conducted by Mehrad Rogha et al. 5 in 2014 on 36 patients and Yagna bahadhur et al. ${ }^{10}$ in 2019 on 30 patients, tegmen plate erosion was same both on HRCT and intra operatively. Sigmoid sinus erosion was found in 2 cases both on HRCT and intraoperatively in our study. Study done by Mehrad Rogha et al. ${ }^{5}$ in 2014 on 36 patients and Sirigiri et al. ${ }^{11}$ in 2012 on 25 patients showed good radiosurgical relation for sigmoid sinus erosion. Tegmen plate erosion and sigmoid sinus erosion seen in our study was almost similar to the above mentioned studies.

\section{CONCLUSIONS}

HRCT temporal bone has enabled the preoperative delineation of the cholesteatoma and the recognition of its complications. HRCT alerts the surgeon for the potential surgical complications of the disease. In our study, HRCT imaging for COM - squamosal type, accurately depicted the soft tissue mass, erosion of tegmen plate, sigmoid sinus plate, scutum, lateral semi-circular canal fistula, incus and supra structure of stapes erosion and same was found intraoperatively whereas on HRCT temporal bone we could not accurately depict the integrity of foot plate of stapes and facial canal erosion. Our study showed good comparison between the preoperative HRCT scans and the surgical findings in cholesteatoma cases. HRCT is confirmed to be valuable in the diagnosis and in guiding the surgical management of cholesteatoma. HRCT temporal bone, has limitations of more radiation exposure and higher costs. It serves as the road map to assist the surgeon during surgery.

\section{Limitations of the Study}

Taking the overall incidence and prevalence of squamosal chronic otitis media i.e. 9.2 per $1,00,000$ population, the total sample was limited to 30 , and also due to the pandemic we were not able to collect more than 30 patients for that stipulated time period.

Data sharing statement provided by the authors is available with the full text of this article at jemds.com.

Financial or other competing interests: None.

Disclosure forms provided by the authors are available with the full text of this article at jemds.com.

\section{REFERENCES}

[1] Browning GG, Weir J, Kelly G, et al.. Chronic Otitis Media. In: Watkinson JC, Clarke RW, eds. Scott-Brown's Otorhinolaryngology head \& neck surgery. $8^{\text {th }}$ edn. New York: CRC Press 2018:1002-8.

[2] Vavassori GE, Hemmati M. Imaging of temporal bone. Chap. 13. $6^{\text {th }}$ edn. In: Glasscock-shambaugh surgery of the ear. USA: People's Medical Publishing House 2010:255.

[3] Datta G, Mohan C, Mahajan M, et al.. Correlation of preoperative HRCT findings with surgical findings in unsafe CSOM. J Dent Med Sci 2014;13(1):120-5.

[4] Prata AAS, Antunes ML, De Abreu CEC, et al.. Comparative study between radiological and surgical findings in chronic otitis media. International of Archives of Otorhinolaryngology 2011;15(1):72-8.

[5] Rogha M, Hashemi SM, Mokhtarinejad F, et al.. Comparision of preoperative temporal bone CT with intraoperative findings in patients with cholesteatoma. Iran J Otorhinolaryngol 2014;26(1):7-12.

[6] Kulkarni SV, Bhagat MB, Burse KS, et al.. A study of correlation between clinical features, radiological and operative findings in safe and unsafe CSOM. MVP J Med Sci 2019;6(1):1-7.

[7] Nanjaraj CP, Nagarajegowda PH, Kannan VP, et al.. Chronic otitis media: high resolution computed tomography evaluation of the temporal bone with surgical correlation. J Evid Based Med Healthc 2016;3(40):1955-62.

[8] Madan G, Turamanlar 0, Bucak A, et al.. Comparision of preoperative temporal bone HRCT and intraoperative findings in patients with chronic otitis media. Erciyes Med J 2015;37(4):138-42.

[9] Nath RK, Das BK, Thakur MKR, et al.. comparative study of findings of preoperative computerized tomography of mastoids with intraoperative findings in cases with CSOM. J Evolution Med Dent Sci 2016;5(79):5882-4.

[10] Rokaya YB, Shahi P. Comparision of high resolution computed tomography with intraoperative findings in patient with chronic suppurative otitis media, NAMS, Bir Hospital, Kathmandu, Nepal. Journal of Karnali Academy of Health Sciences 2019;2(2):89-97.

[11] Sirigiri RR, Dwarakanath K. Correlative study of HRCT in squamosal type of chronic otitis media. Indian J Otolaryngology Head and Neck Surgery 2012;63(2):1558. 